\title{
Down-regulating cyclin-dependent kinase 9 of alloreactive CD4+ T cells prolongs allograft survival
}

\author{
Yang Zhan ${ }^{1}$, Yeming Han'ㄹ, Hukui Sun ${ }^{1}$, Ting Liang ${ }^{1}$, Chao Zhang ${ }^{1}$, Jing Song ${ }^{1}$ and \\ Guihua Hou ${ }^{1}$ \\ ${ }^{1}$ Laboratory of Experimental Teratology, Ministry of Education and Institute of Experimental Nuclear Medicine, School of \\ Medicine, Shandong University, Jinan, Shandong, China \\ ${ }^{2}$ Key Laboratory of Cardiovascular Remodeling and Function Research, Chinese Ministry of Education and Chinese Ministry \\ of Health, Department of Cardiology, Qilu Hospital, Shandong University, Jinan, Shandong, China
}

Correspondence to: Guihua Hou, email: ghhou@sdu.edu.cn

Keywords: CDK9, cytokines, allorejection, tolerance, CD4 ${ }^{+}$T cell, Immunology and Microbiology Section, Immune response, Immunity

Received: December 14,2015 Accepted: April 06, $2016 \quad$ Published: April 18, 2016

\section{ABSTRACT}

CDK9 (Cyclin-dependent kinase 9)/Cyclin T1/RNA polymerase II pathway has been demonstrated to promote the development of several inflammatory diseases, such as arthritis or atherosclerosis, however, its roles in allotransplantation rejection have not been addressed. Here, we found that CDK9/Cyclin T1 were apparently upregulated in the allogeneic group, which was positively correlated with allograft damage. CDK9 was inhibited obviously in naive splenic CD4 ${ }^{+} \mathrm{T}$ cells treated $6 \mathrm{~h}$ with $3 \mu$ M PHA767491 (a CDK9 inhibitor), and adoptive transfer of these CD4 ${ }^{+} \mathrm{T}$ cells into allografted SCID mice resulted in prolonged survival compared with the group without PHA767491 pretreated. Decelerated rejection was correlated with enhanced IL-4 and IL-10 production and with decreased IFN-Y production by alloreactive $T$ cells. More

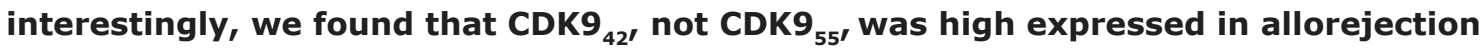
group, which could be prominently dampened with PHA767491 treatment. The expression of $\mathrm{CDK9}_{42}$ was consistent with its downstream molecule RNA polymerase II. Altogether, our findings revealed the crucial role of CDK9/Cyclin T1/Pol II pathway in promoting allorejection at multiple levels and may provide a new approach for transplantation tolerance induction through targeting CDK9.

\section{INTRODUCTION}

The main goal of transplantation immunology research is to induce donor-specific tolerance and to decrease the lifelong need of anti-rejection drugs. Allorejection is mainly mediated by alloreactive $\mathrm{CD} 4^{+}$and $\mathrm{CD}^{+} \mathrm{T}$ cells, and $\mathrm{CD} 4^{+} \mathrm{T}$ cells have emerged as the most critical factor that may induce allograft destruction in the absence of $\mathrm{CD} 8^{+} \mathrm{T}$ cells, and depletion of peripheral $\mathrm{CD} 4^{+}$ $\mathrm{T}$ cells could apparently prolong allograft survival [1-4]. The current anti-rejection drugs using in clinic, including mTOR and Stat/Jak inhibitors, target only a few genes activated by inflammatory signaling and whose efficacy is limited to particular pathways $[5,6]$. Therefore, a strategy that effectively suppresses de novo inflammation by targeting many more primary response genes in allografts may prevent or delay the onset of allorejection.

CDK9, a component of the positive transcription elongation factor $\mathrm{b}(\mathrm{P}-\mathrm{TEFb})$ kinase, regulates the transcriptional activity of primary response genes by phosphorylating the RNA polymerase II C-terminal domain upon exposure to certain stimuli $[7,8]$. Accumulating evidences support a crucial role for CDK9 in monitoring the activation of primary inflammatory response genes and controlling inflammatory processes [9-13]. The differential distribution and regulation of the two isoforms of CDK9, $\mathrm{CDK} 9_{42}$ and $\mathrm{CDK} 9_{55}$, may allow greater control of $\mathrm{P}-\mathrm{TEFb}$ activities under varying cellular states [14-16]. Furthermore, it was reported that $\mathrm{CDK} 9_{42}$ was localized diffusely in the nucleoplasm, while the CDK9 ${ }_{55}$ accumulated in the nucleolus [17].

Thus, this study aimed to investigate whether PHA767491 (a novel selective CDK9 inhibitor) could prolong survival of allografts through reducing the activity of donor-reactive $\mathrm{CD} 4^{+} \mathrm{T}$ cells and which isoform of $\mathrm{CDK} 9$ predominantly acts in $\mathrm{CD} 4^{+} \mathrm{T}$ cells activation under allorejection. 


\section{RESULTS}

\section{CDK9 up-regulates allorejection}

To investigate the expression of CDK9 during the process of allorejection, we established both syngeneic and allogeneic mouse skin transplant models. Skin grafts were collected on days 4, 8, 12 and 16 after transplantation, and CDK9 and Cyclin T1 mRNA expression levels were quantified. As shown in Figure 1A, CDK9 mRNA significantly up-regulated at the peak rejection period (day 12). As the rejection remitted (day 16), CDK9 expression decreased (Figure 1A). The levels of Cyclin T1 were similar to those of CDK9 (Figure 1B). The expression of CDK9 and Cyclin T1 levels were both dramatically higher in the allogeneic group than in the syngeneic group from day 8 to day 16 (Figure 1A, 1B), especially at day 12, suggesting that CDK9 expression positively correlated

\section{B}

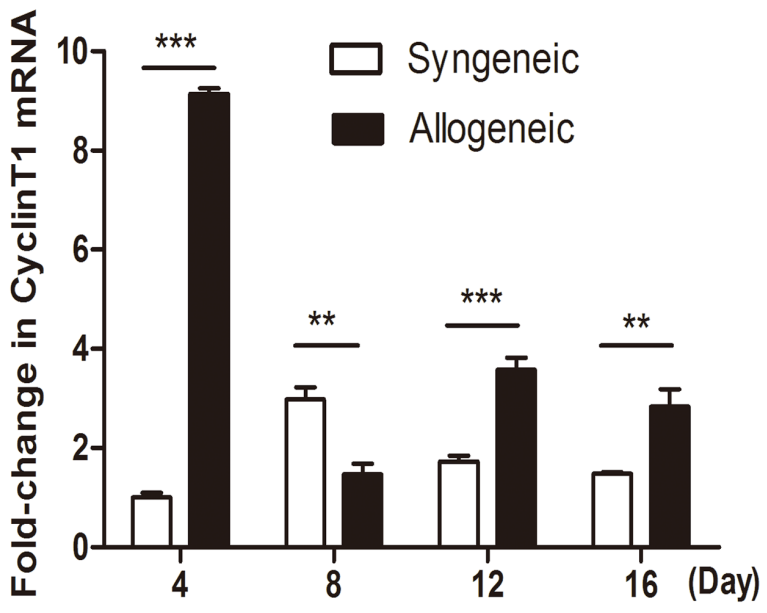

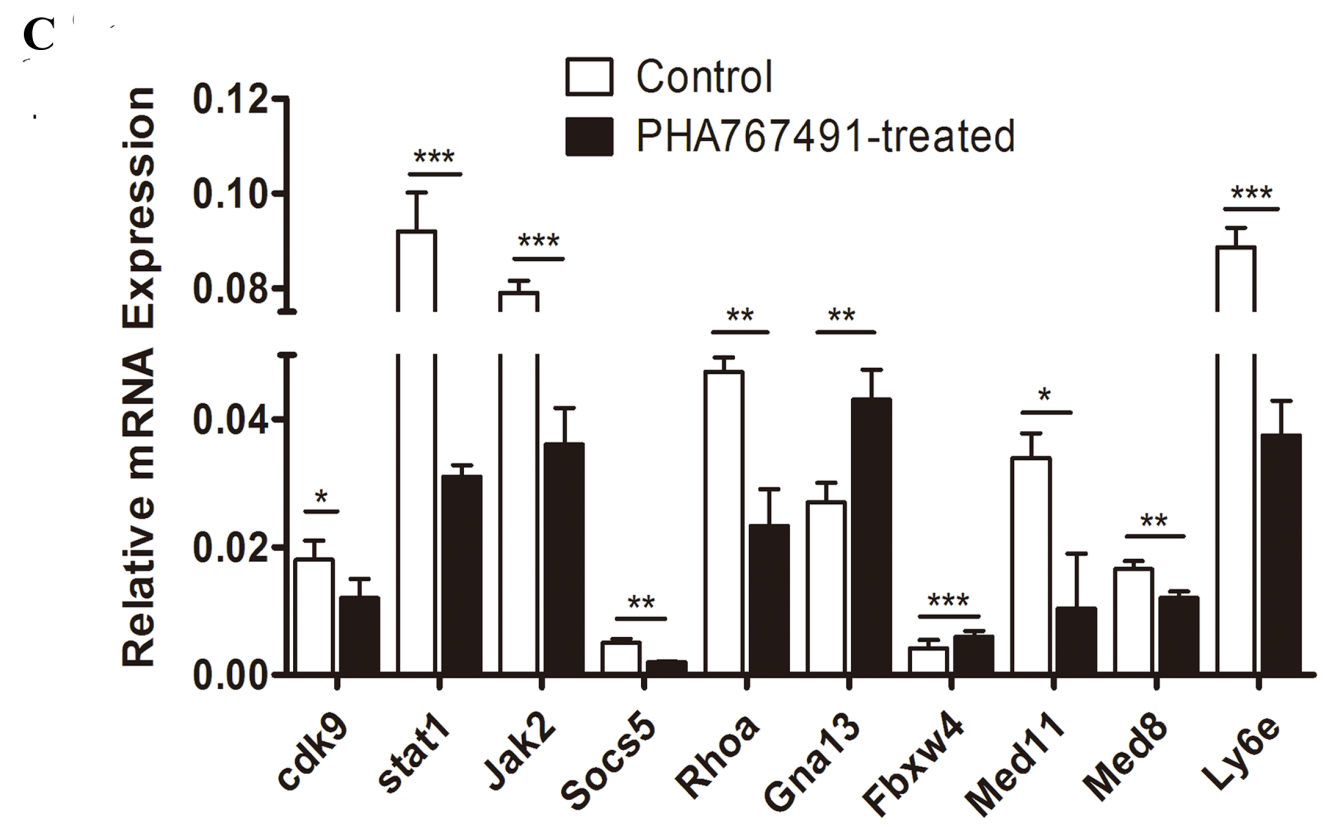

Figure 1: CDK9 is positively associated with the severity of allorejection. A.-B. CDK9 and Cyclin T1 mRNA expression enhanced in allogeneic recipients. The results of Q-RT-PCR assays plotting the fold changes in CDK9 (A) and Cyclin T1 (B) in syngeneic day 4 skin grafts normalized to GAPDH are shown. C. CDK9 regulates rejection-related genes in alloreactive $\mathrm{CD} 4^{+} \mathrm{T}$ cells. Cells were isolated from allogeneic transplant recipients at day 12 and then treated with $3 \mu \mathrm{M}$ PHA767491 or PBS for $2 \mathrm{~h}$ followed by assay of reporter gene expression assay. The data are presented as the means \pm s.d. from three independent experiments. The data are analyzed by Student's $\mathrm{t}$ test. ${ }^{*} p<0.05, * * p<0.01, * * * p<0.001$. 
with the severity of allorejection.

To further understands the functions of CDK9 in allorejetion, we validated some genes from a $\mathrm{CD}^{+}$ $\mathrm{T}$ cell-mediated allorejection SAGE (serial analysis of gene expression) library previously published by our lab [18]. Splenic $\mathrm{CD}^{+} \mathrm{T}$ cells were isolated from allogeneic transplant mice on day 12 , and then treated with $3 \mu \mathrm{M}$ PHA767491 ( dose-effect of PHA767491 was shown in Supplementary Figure 2) for 2h. As shown in Figure 1C, CDK9 inhibition resulted in dramatic down-regulation in Stat1 (by 66.3\%), Jak2 (by 54.4\%), Socs 5 (by 60\%), RhoA (by 50.8\%), Ly6e (by 57.8\%), Med8 (by 27.3\%), and Med11 (by 69.5\%) expression, as well as significant up-regulation of Gna13 (by 59.3\%) and Fbxw4 (by 43.9\%) expression. These genes contribute to allorejection, and are mainly involved in transcription (Med8 and Med11), activation (Ly6e), proliferation (Stat1/Jak2 and Socs5),

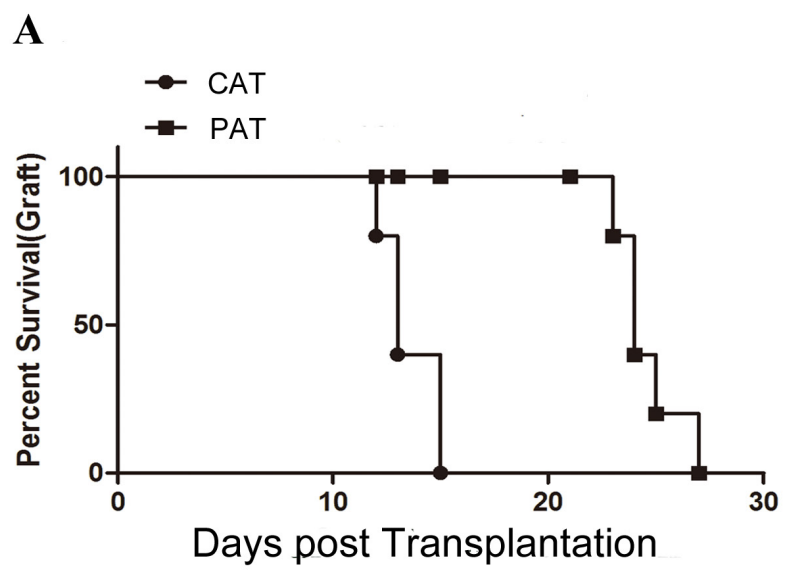

$\mathbf{C}$ CAT

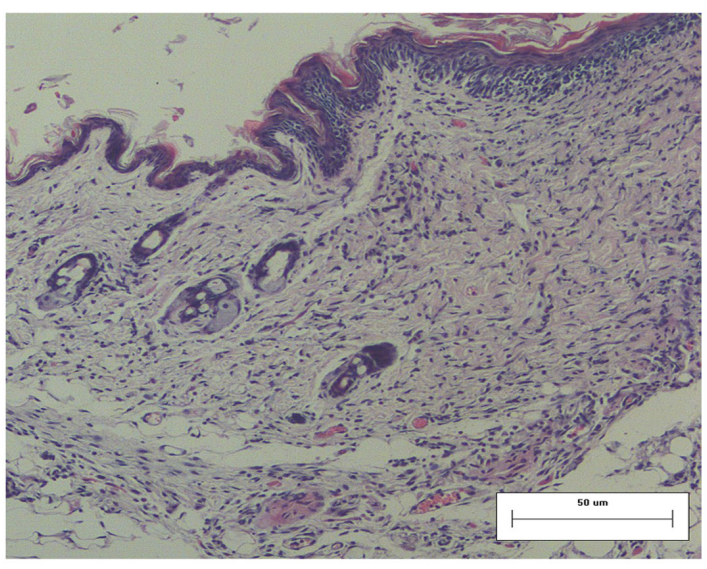

adhesion and movement (RhoA, Gna13, and Fbxw4) [1925]. Our results suggested that CDK9 played a prominent and comprehensive role in promoting the occurrence and development of allorejection at multiple levels.

\section{CDK9 inhibition of $\mathrm{CD}^{+} \mathrm{T}$ cells prolongs allograft survival}

To investigate the effect of CDK9 inhibition of $\mathrm{CD}^{+} \mathrm{T}$ cells in prolonging allograft survival, SCID allogeneic skin transplantation models were constructed, and naive $\mathrm{CD}^{+} \mathrm{T}$ cells pretreated with PHA767491 (PAT) or PBS (CAT) were adoptively transferred. As shown in Figure 2A and 2B, allorejection occurred in the PAT group on days 23 27, whereas on days $12 \sim 15$ in CAT group. Approximately $46 \%$ of the recipients in the PAT group achieved long-term survival $(p=0.014)$.

B

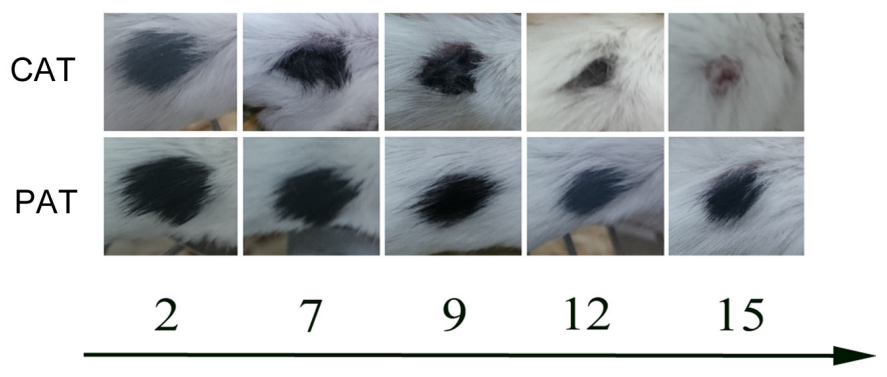

Days post Transplantation

\section{PAT}

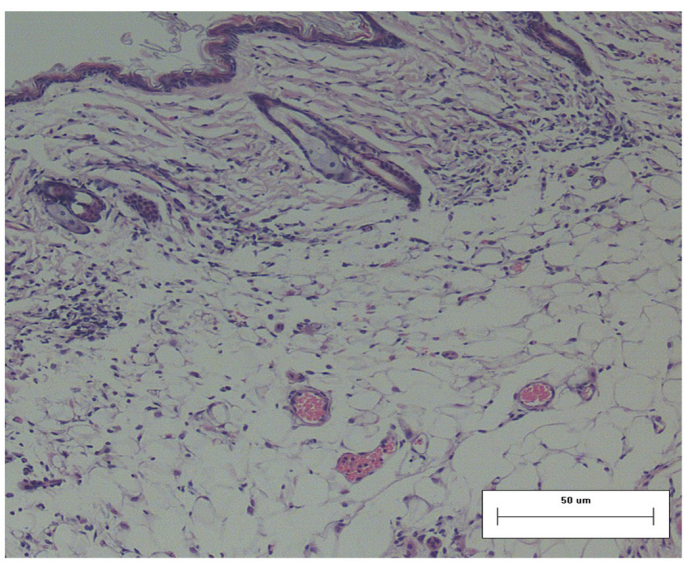

Figure 2: Adoptive transfer of PHA767491-pretreated CD4 ${ }^{+}$T cells prolongs skin allograft survival. A. SCID allogeneic skin transplant recipients received $1 \times 10^{7}$ PHA767491-pretreated $\mathrm{CD}^{+} \mathrm{T}$ cells (PAT group) at three weeks post-transplantation. Control mice underwent adoptive transfer of PBS-pretreated CD4 ${ }^{+} \mathrm{T}$ (CAT group) at three weeks post-transplantation. $(n=5)$. B. Survival times and conditions of skin allografts. The data are representative of three independent experiments. C. HE staining of skin allografts sections. 
Graft histological assay showed obviously inflammatory infiltration and tissue necrosis in the CAT group while an apparent decrease of inflammation and necrosis was observed in the PAT group (Figure 2C). In addition, the toxicity and the optimal concentration of PHA767491 in vivo $(3 \mathrm{mg} / \mathrm{kg})$ were determined. Consistent with the adoptive transfer experiment, this dose of PHA767491 in vivo administration achieved prolonged graft survival in BALB/c allograft model (Supplementary Figure 1).

\section{Donor-reactive $\mathrm{CD4}^{+} \mathrm{T}$ cell response is weakened in PAT mice}

To further understand the mechanism of CDK9 inhibition prolonged allograft survival, the $\mathrm{CD} 4^{+} \mathrm{T}$ cells adoptive transferred allorecipients were sacrificed on day 12 (acute rejection of the CAT group). Skin graft, $\mathrm{CD}^{+} \mathrm{T}$ cells from spleen and draining lymph node were analyzed

A
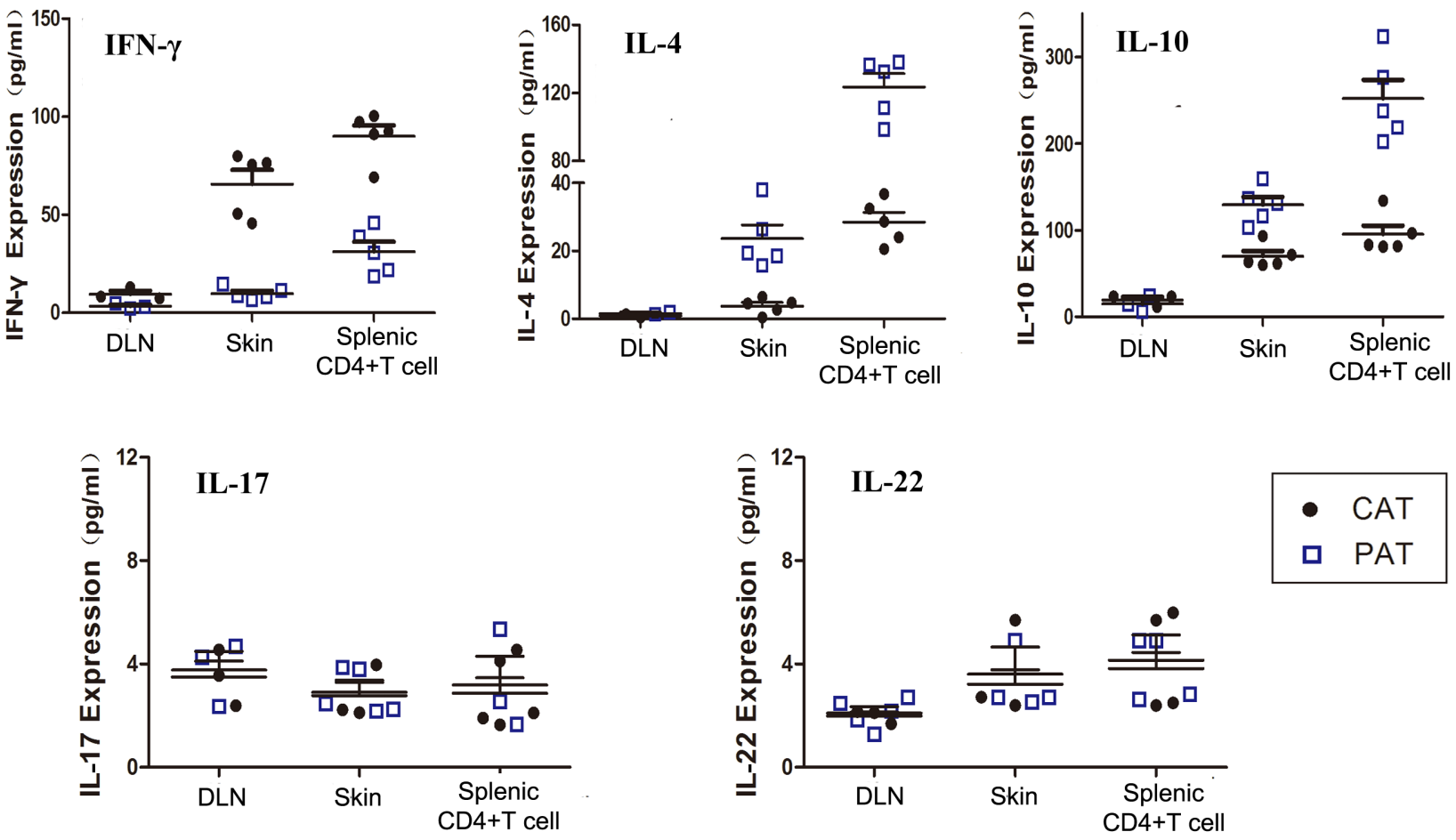

B
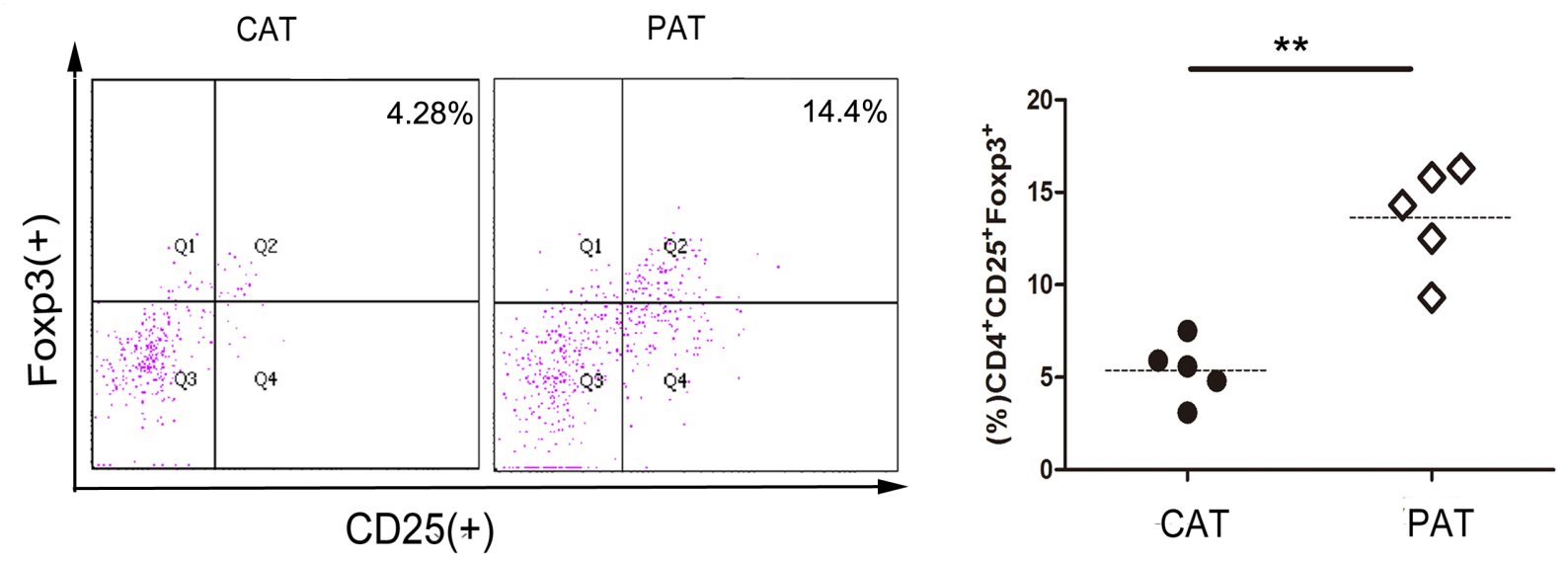

Figure 3: PAT recipients exhibit decreased anti-donor immunity and graft inflammation. Analysis was performed on day 12 post adoptive transfer. A. The expression of IFN- $\gamma$, IL-4, IL-10, IL-17, and IL-22 in cells and tissues was analyzed by multiple cytokines array. Each data point represents an individual mouse. $(n=5)$. $* * p<0.01$, for unpaired t test between CAT and PAT mouse. B. Splenocytes frequencies of Treg were determined by flow cytometry. $(n=5)$. 
by antibody array and flow cytometry. PHA767491 treatment apparently suppressed the expression of Th1type cytokine IFN- $\gamma$ by 8.2 -fold in allografts, by 6.7 -fold in splenic $\mathrm{CD}^{+} \mathrm{T}$ cells, and obviously increased Th2-type cytokines IL-4 and IL-10 by 4.8 and 1.9 fold in allografts, and by 4.3 -fold and 2.6-fold in splenic $\mathrm{CD}^{+} \mathrm{T}$ cells, respectively (Figure $3 \mathrm{~A}$ ), while no obvious change was detected in draining lymph node. And also, no significant changes in IL-17 and IL-22 expression were detected in graft, splenic $\mathrm{CD}^{+} \mathrm{T}$ cells or draining lymph node (Figure 3A). In addition, we observed a marked increase of splenic Tregs (regulatory T cells) in the PAT group (Figure 3B). These results indicated that CDK9 inhibition may weaken the anti-donor response by a predominance of Th2 and Tregs, and independent of Th17 and Th22 cells.

To investigate whether CDK9 promotes allorejection in the activation stage, we isolated the recipients' splenic Teffs (effector T cells) at day 7 post transplantation, and we found that PHA767491 suppressed the activation of alloreactive Teffs. The expression of CD69, CD25 and IL-2 was decreased by $47.3 \%, 22.9 \%$ or $44.9 \%$ in the PAT group, respectively (Figure 4A, 4B). PHA767491 suppressed the activation of alloreactive Teffs.

\section{PHA767491 decreases Teffs proliferation without change of Tregs proliferative and suppressive capacities}

We also detected the effects of CDK9 inhibition on regulatory $\mathrm{T}$ cells and Teffs proliferation at day $0,1,3$, 5 and 7 with anti-CD3/anti-CD28 mAb stimulation. As expected, Teffs expanded robustly in the control group and poorly in $3 \mu \mathrm{M}$ PHA767491-treated group (Figure 5A). Overall, Tregs expansion in $3 \mu \mathrm{M}$ PHA767491-treated group showed no difference compared with control group, and the proliferation of two groups considerably increased by 2.8 -fold and 2.9-fold respectively on day 7 compared to that on day 1 (Figure 5B).

The effects of PHA767491 on the regulatory activities of Tregs were analyzed after treatment with $3 \mu \mathrm{M}$ or $5 \mu \mathrm{M}$ PHA767491. The proliferation of Teffs stimulated by anti-CD3/anti-CD28 mAb was significantly lower when the cells were co-cultured with untreated Tregs, and the higher Treg:Teff ratios had stronger inhibition effects on proliferation. However, no obvious change was observed between co-cultured with pretreatedTregs and untreated control Tregs (Figure 5C, 5D). The results indicated that CDK9 inhibition showed no apparent influence on the suppressive capacity of Tregs.
A

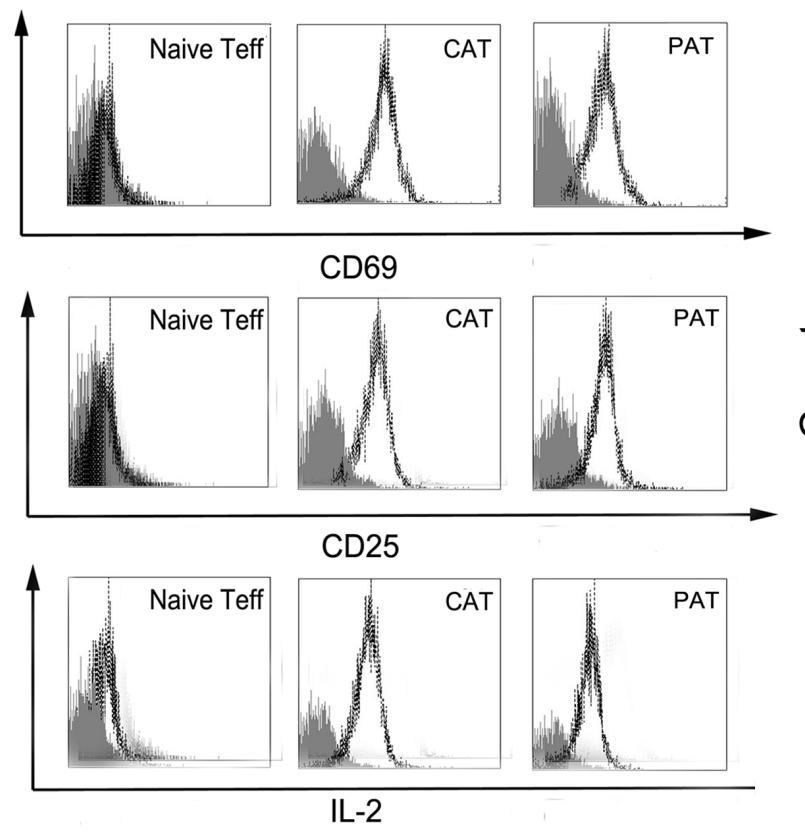

B

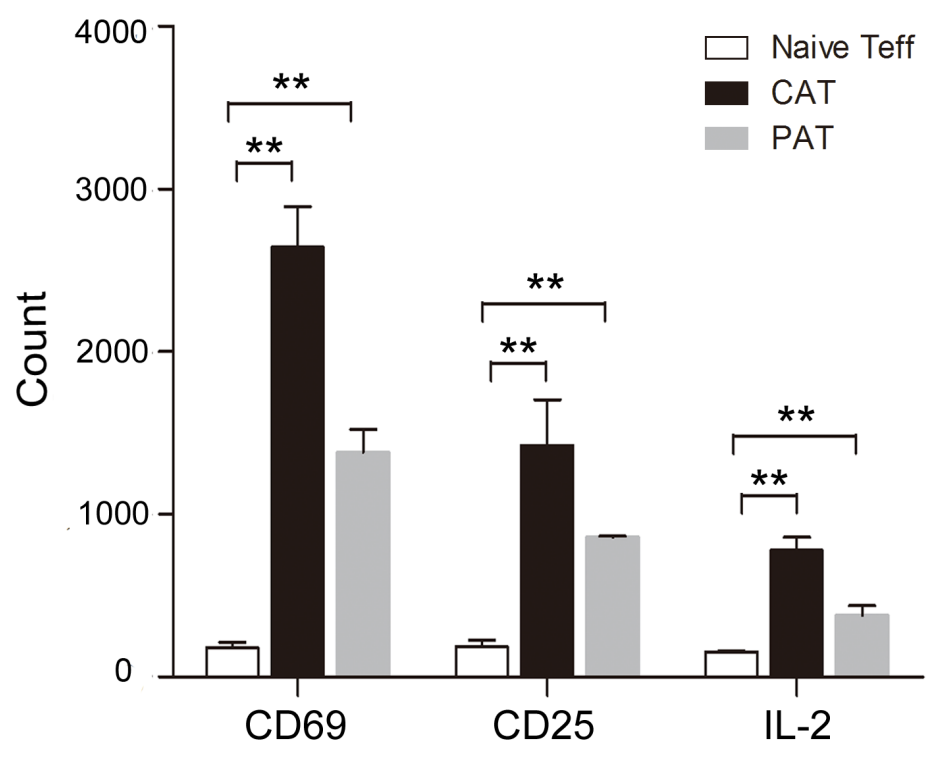

Figure 4: PHA767491 inhibits the activation of alloreactive Teffs. A. Representative fluorescence histograms demonstrate decreased expression of CD69 and CD25 and intracellular expression of IL-2 in PAT splenic Teffs. Normal lines: isotype-match negative control; black lines: experimental group. B. Geometric mean fluorescence intensity ratio \pm SEM shows alternative expression. (3-5 mice per group). $* * p<0.01$. 
PHA767491 shows greater CDK9 ${ }_{42}$ inhibition than $\mathrm{CDK}_{55}$ in $\mathrm{CD4}^{+} \mathrm{T}$ cells

In our preliminary experiments, we found that CDK $9_{42}$ was more sensitive to $3 \mu \mathrm{M}$ PHA767491 treatment than $\mathrm{CDK}_{55}$, total CDK9 $\left(\mathrm{CDK} 9_{42+55}\right)$ levels decreased by $54.2 \%$, while $\mathrm{CDK}_{42}$ levels reduced by $66.6 \%$ and CDK ${ }_{55}$ levels reduced by $37.9 \%$ (Supplementary Figure 2 ). We next examined the expression and localization of these two isoforms in alloantigen-stimulated $\mathrm{CD}^{+} \mathrm{T}$ cells pretreated with or without PHA767491 for $2 \mathrm{~h}$. Along with the stimulation of alloantigens, $\mathrm{CDK} 9_{42} / \mathrm{CDK} 9_{(42+55)}$ were increased by $35.1 \%$ at $30 \mathrm{~min}$ and by $48 \%$ at $60 \mathrm{~min}$ in the control group. While $\mathrm{CDK} 9_{42} / \mathrm{CDK} 9_{(42+55)}$ was persistently decreased in the PHA767491 treated group from 15 to 60min (Figure 6B). RNA Pol II expression was consistent with $\mathrm{CDK} 9_{42}$ expression (Figure 6B, 6D), but not consistent with $\mathrm{CDK}_{55}$ expression. Immunofluorescence assay confirmed this result. The subcellular localization of CDK9 expression gradually moved from the nucleolus $\left(\mathrm{CDK}_{55}\right)$ to nuclear speckles $\left(\mathrm{CDK}_{42}\right)$ in the control group, while PHA767491 attenuated this translocation of CDK $9_{42}$ (Figure 7). These data indicate that $\mathrm{CDK} 9_{42}$, not CDK $9_{55}$, has the dominant role in allorejection.

\section{DISCUSSION}

The key findings of this study include: (1) CDK9 is positively associated with the severity of allorejection, (2) CDK9 promotes activation and proliferation in alloreactive $\mathrm{CD}^{+} \mathrm{T}$ cells, and (3) $\mathrm{CDK} 9_{42}$, not $\mathrm{CDK} 9_{55}$, enhances alloresponse.

A variety of inflammatory cells and molecules, including neutrophils, lymphocytes, vascular endothelial cells, complement and cytokines, participate in the development of allorejection [26]. Effectively limiting the development of inflammation will greatly delay allorejection. Evidence indicates that CDK9 is the primary target of flavopiridol responsible for its profound anti-
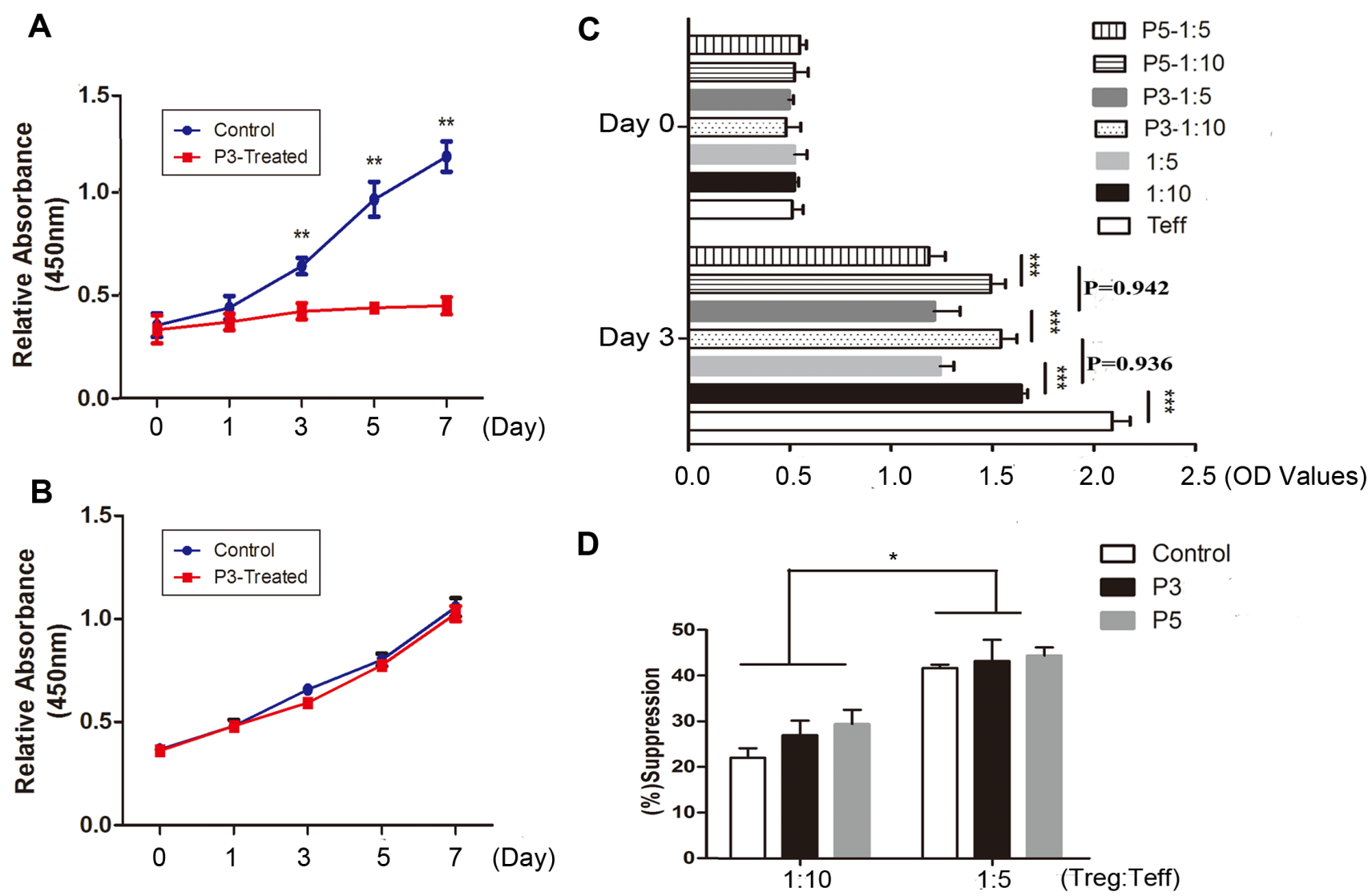

Figure 5: PHA767491 decreases Teffs proliferation without change of Tregs proliferative and suppressive capacity. A.-B. Proliferation of Teffs (A) and Tregs (B) which were incubated for 7 days in the presence of $2 \mu \mathrm{g} / \mathrm{ml}$ anti-CD3 $\mathrm{mAb}$ and $1 \mu \mathrm{g} / \mathrm{ml}$ antiCD28 mAb with $3 \mu \mathrm{M}$ PHA767491 or PBS. C.-D. A suppression assay was performed in which Teffs were co-cultured with PHA767491 (3 $\mu \mathrm{M}$ or $5 \mu \mathrm{M})$ or PBS-pretreated Tregs at a ratio of 5 to 1 or 10 to 1 . Representative proliferation $(\mathrm{C})$ and quantitative suppressive capacities (D) are shown. $* p<0.05, * * p<0.01, * * * p<0.001$. 
inflammatory effects in vitro $[10,11]$. CDK9 is involved in a central mechanism that activates primary inflammatory response gene transcription in human chondrocytes [7]. CDK9 inhibition has previously been shown to block the CDK9-activated NF- $\mathrm{KB}$ pathway to induce strong antiinflammatory effects in human endothelial cells [27-30]. IL-6 induces CDK9 to bind to Stat3 in the nucleus to abrogate the suppression of $\mathrm{p} 21$ by DRB [31, 32].

In our previous work, we identified differentially expressed genes in mouse alloreactive $\mathrm{CD}^{+} \mathrm{T}$ cells using the SAGE method [18]. Because $\mathrm{CD}^{+} \mathrm{T}$ cells are principal contributors to rejection, we selected several genes from this SAGE library and found that CDK9 promoted transcription, cellular activation and proliferation via these genes during $\mathrm{CD}^{+} \mathrm{T}$ cell-mediated mouse skin allorejection.

Consistent with prolonged survival of allograft, the inflammatory responses mediated by Th1 cells in the graft site were alleviated in PAT mice, and PHA767491 induced Th2 and Treg differentiation. Significant difference in Th17 was not detected in our experiment which may be due to that it mainly participates in the recruitment of neutrophils $[33,34]$. Here, we focused on the allorejection, which is mainly mediated by Th1/Th2 cells. Additionally, Th22 cells have been shown to possibly contribute to skin transplant rejection $[35,36]$. However, the effect of Th22 cells was not detected in our study of allorejection promoting function of CDK9.

It was reported that Tregs could suppress the inflammatory response and alleviate rejection through
A

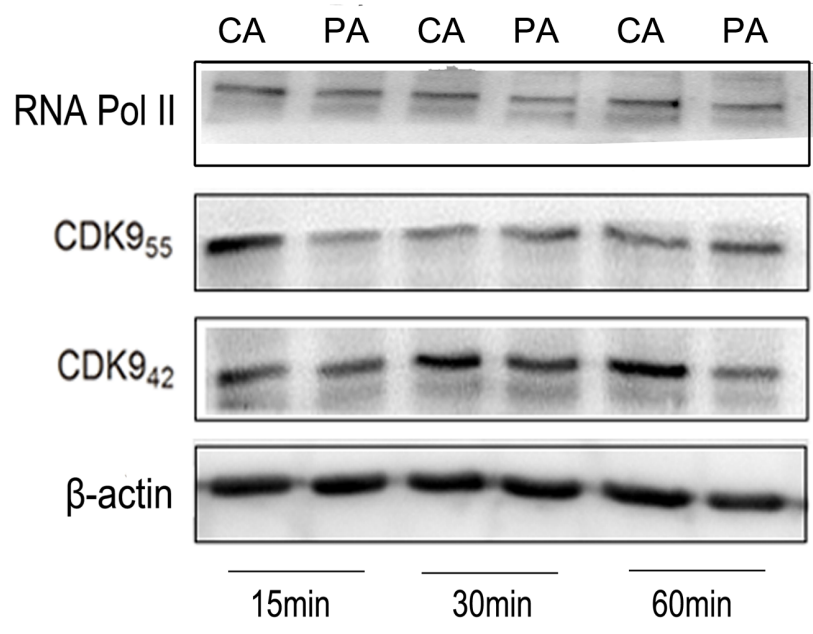

C

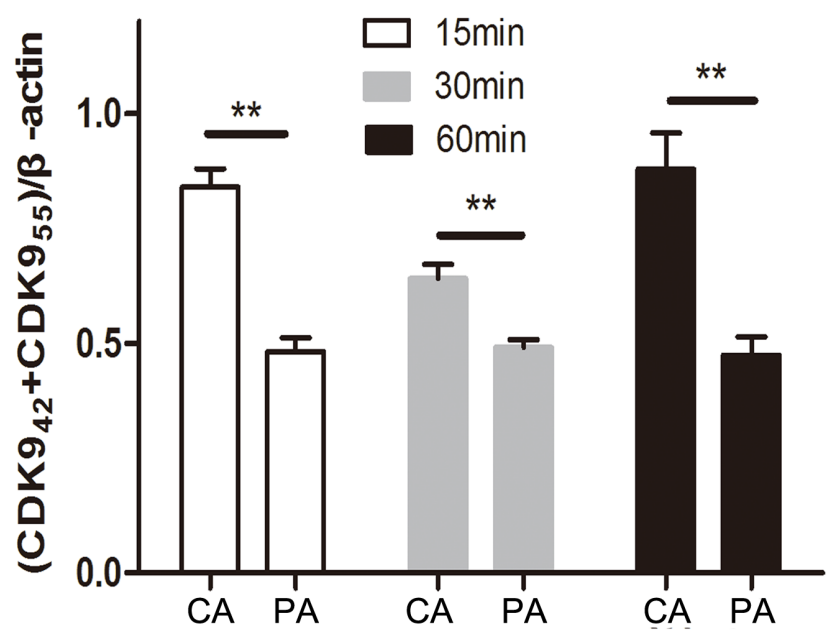

B

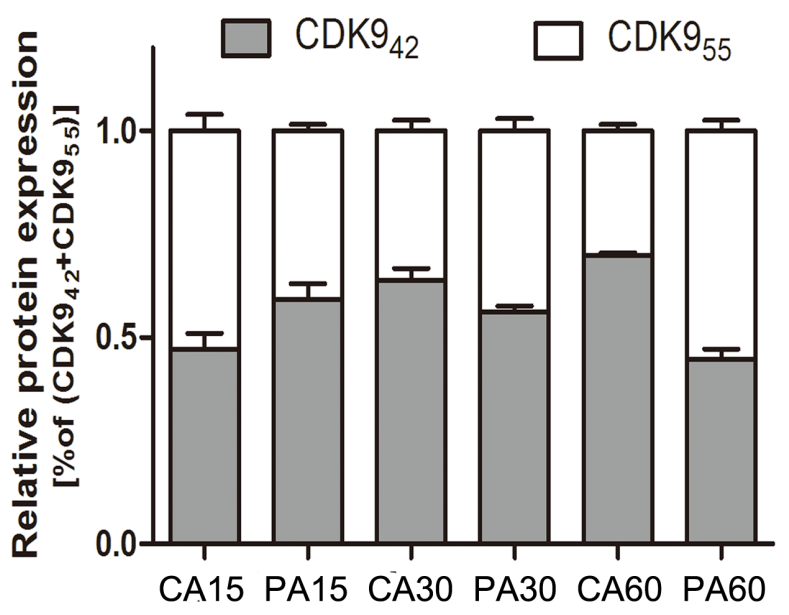

D

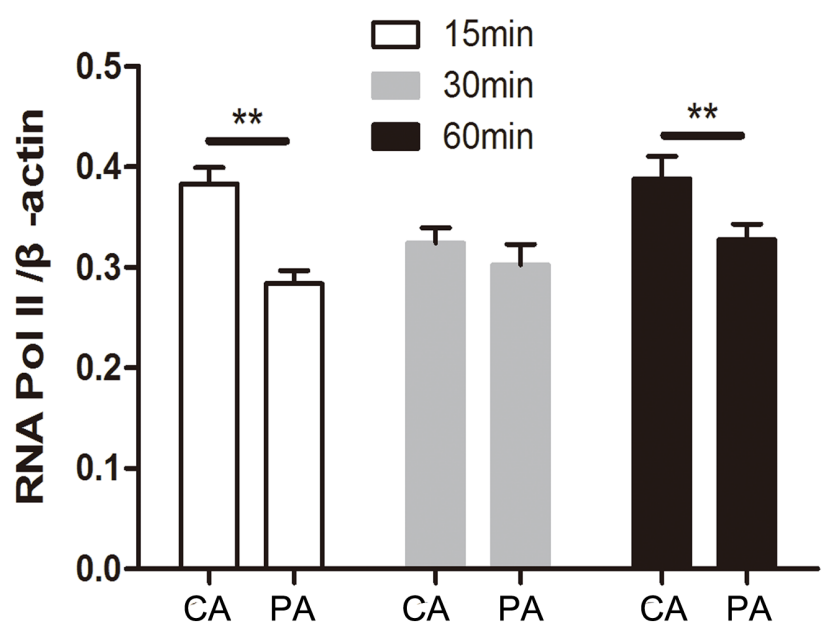

Figure 6: PHA767491 dominantly dampens CDK9 ${ }_{42}$ in CD4 $^{+}$T cells. A. Western blot detection of RNA Pol II, CDK9 ${ }_{55}, \mathrm{CDK} 9_{42}$ and $\beta$-actin expression in antigen-activated $(2 \mu \mathrm{g} / \mathrm{ml}$ anti-CD3 $\mathrm{mAb}$ and $1 \mu \mathrm{g} / \mathrm{ml}$ anti-CD28 mAb $) \mathrm{CD}^{+} \mathrm{T}$ cells pretreated with $3 \mu \mathrm{M}$ PHA767491 or PBS for 2 h. B.-D. The blot and gray value are shown. Similar results were observed in three independent experiments. $* * p<0.01$. 
inhibiting on Teffs. And most of immunosuppressants primarily affect Tregs. However, our data indicated that CDK9 inhibition prolonged the allorejection response without apparent impact on Tregs. We also found that the suppressive effect of PHA767491 was much stronger on Teffs than Tregs. .

CDK9 is known as an effective target for eliciting apoptosis [37], so we investigate whether PHA767491 suppresses Teff activity via an apoptotic pathway. We found that PHA767491 promoted early apoptosis with allo-antigen stimulation and no effect upon the cell cycle (Supplementary Figure 3).

The $\mathrm{CDK}_{42}$ isoform has been shown to play a more important role than $\mathrm{CDK} 9_{55}$ in responding to a variety of stimuli. Therefore, we investigated the effect of PHA767491 on isoforms CDK9 ${ }_{55}$ and CDK $9_{42}$ respectively. Consistent with a previous report [14], the ratio of $\mathrm{CDK} 9_{55}$ to $\mathrm{CDK} 9_{42}$ significantly decreased in activated $\mathrm{CD}^{+}{ }^{+} \mathrm{T}$ cells, however, PHA767491 treatment reversed this pattern, inhibiting $\mathrm{CDK} 9_{42}$ expression
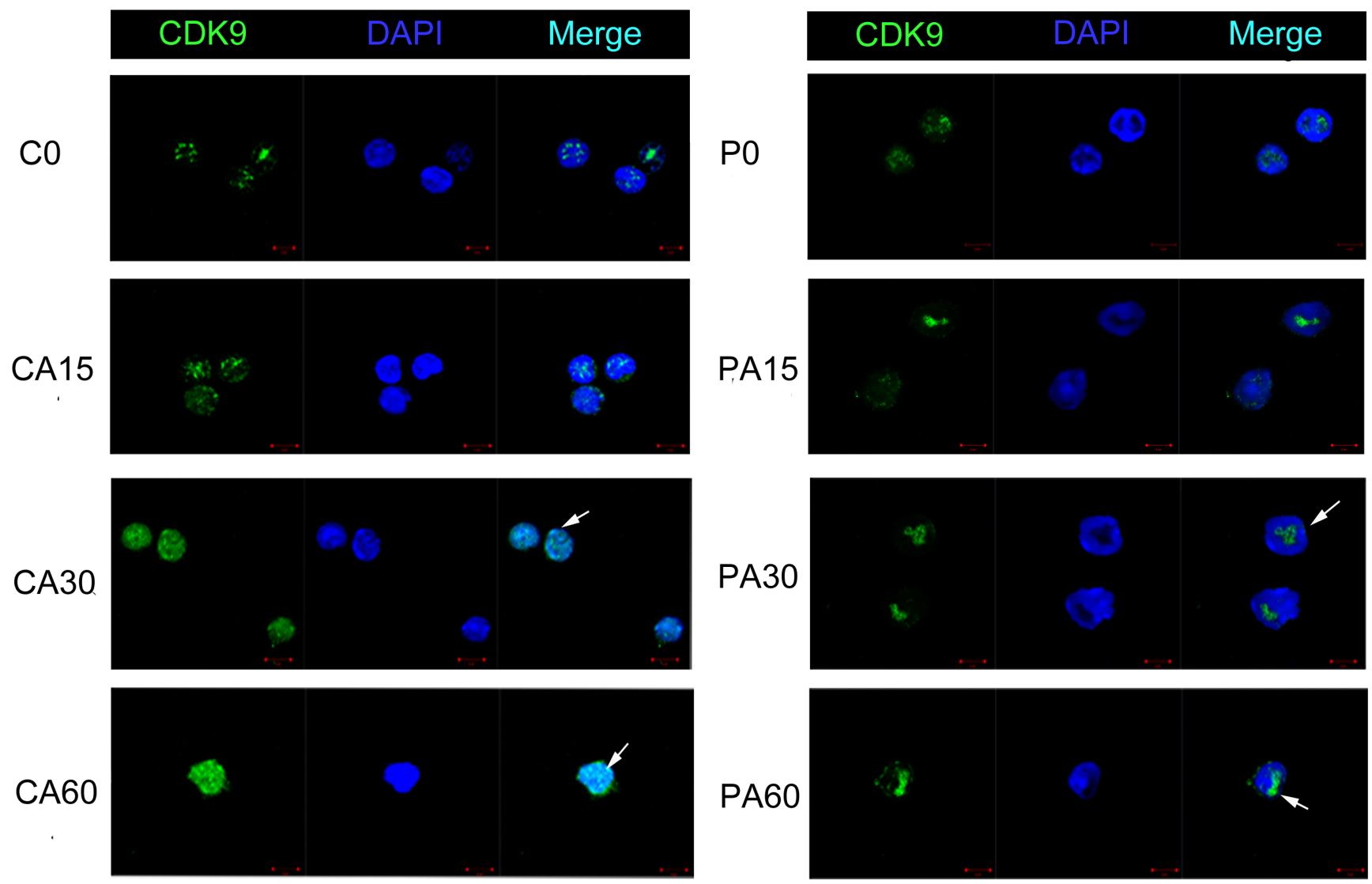

Figure 7: $\mathrm{PHA}_{767491}$ alters the subcellular distribution of $\mathrm{CDK}_{42}$ and $\mathrm{CDK}_{55}$ in CD4 $^{+} \mathrm{T}_{\text {cells. Immunofluorescence staining }}$ for changes in the expression of $\mathrm{CDK} 9_{42}$ and $\mathrm{CDK} 9_{55}$ in alloantigen-activated CD4 ${ }^{+} \mathrm{T}$ cells pretreated with PBS or $3 \mu \mathrm{M}$ PHA767491. Scale bar: $5 \mathrm{~mm}$. Cell nuclei were identified by DAPI staining (blue). PHA767491 pretreatment abrogated alloantigen-induced up-regulation of $\mathrm{CDK} 9_{42}$ expression, but preserved $\mathrm{CDK} 9_{55}$ expression. All data are representative of three independent experiments $(n=4)$. 


\section{MATERIALS AND METHODS}

\section{Animals}

Female BALB/c (H-2d) and C57BL/6 (H-2b) mice weighing $18 \pm 2 \mathrm{~g}$ were purchased from the Laboratory Animal Center, Shandong University. Female SCID (H-2d) mice weighing $18 \pm 2 \mathrm{~g}$ were purchased from the Institute of Laboratory Animal Sciences (Beijing, China). SCID mice were given free access to standard mouse chow and tap water. All mice were treated in strict compliance with protocols approved by the Institutional Animal Care and Use Committee (IACUC). Experiments were performed in accordance with national animal protection guidelines.

\section{Allogeneic and syngeneic skin transplant models}

To establish an allogeneic transplantation model, full-thickness skin grafts from donor C57BL/6 mice were transplanted onto prepared graft beds in the right shoulders of recipient $\mathrm{BALB} / \mathrm{c}$ mice. To establish a syngeneic transplantation model, full-thickness skin grafts from donor $\mathrm{BALB} / \mathrm{c}$ mice were transplanted onto prepared graft beds in the right shoulders of recipient BALB/c mice. Transplantations were performed as previously described [38]. In a separate experiment, mice were treated with normal saline or PHA767491 $(3,10$ or 30 $\mathrm{mg} / \mathrm{kg}$ ) by oral administration on day $1,3,5,7,10$ and 14 post transplantation. Grafts were observed daily after bandages were removed from recipients at day 7 ; rejection was defined as necrosis of more than $90 \%$ of the graft.

\section{SCID allogeneic skin transplant model}

Transplantation was performed as previously described [38]. Briefly, full-thickness skin grafts from donor $\mathrm{C} 57 \mathrm{BL} / 6$ mice were transplanted on $\mathrm{BALB} / \mathrm{c}$ SCID recipients, and the grafts were allowed to heal for approximately 2-3 weeks.

\section{Cell preparation and adoptive transfer}

Single spleen cells suspension of BALB/c mice were prepared according to standard procedures. $\mathrm{CD} 4^{+} \mathrm{T}$ cells were enriched using an EasySep ${ }^{\mathrm{TM}}$ Mouse $\mathrm{CD} 4^{+} \mathrm{T}$ Cell Enrichment Kit (Stemcell Technologies, Vancouver, BC Canada) according to the manufacturer's instructions. Tregs were isolated using an EasySep ${ }^{\mathrm{TM}}$ Mouse $\mathrm{CD} 4^{+} \mathrm{CD} 25^{+}$Regulatory T Cell Isolation Kit (Stemcell Technologies, Vancouver, BC Canada). The magnetically labeled $\mathrm{CD} 4{ }^{+} \mathrm{CD} 25^{+} \mathrm{T}$ cells were remained inside the tube, and $\mathrm{CD} 4{ }^{+} \mathrm{CD} 25^{\text {neg }} \mathrm{T}$ cells (Teffs) in the supernatant were purified for use.

For the adoptive transfer experiment, $1 \times 10^{7} \mathrm{CD}^{+}$ $\mathrm{T}$ cells from naive BALB/c mice were treated with $3 \mu \mathrm{M}$ PHA767491 (PAT group) or with the same volume of PBS (CAT group) for $6 \mathrm{~h}$. The cells were washed twice with PBS and then injected intravenously into allo-SCIDrecipients. The graft was observed daily after 7 days, and rejection was defined as graft necrosis of more than $90 \%$.

\section{Quantitative real-time PCR}

Total RNA (2.5 mg) was reverse transcribed into cDNA using a FastQuant RT Kit (TIANGEN BIOTECH, Beijing, China). Quantitative-PCR (qPCR) was performed using SuperMix (Platinum SYBR Green qPCR Kit; CWBIO, Shanghai, China) and a PikoReal 96 system (Thermo Scientific, Schwerte, Germany) as previously described [39]. The specific primer sequences used for CDK9, CyclinT1, Ly6e, Rhoa, Med8, Med11, Socs5, Fbxw4 and Gna13 are included in Table S1.

\section{Antibody array assay of multiple cytokines}

Skin grafts, splenic $\mathrm{CD}^{+} \mathrm{T}$ cells and draining lymph nodes were harvested from PAT or CAT mice at the day 12 post adoptive transfer. The cells and tissue lysates were prepared and analyzed using a multiple cytokine array (Suzhou SJ Biomaterials, Jiangsu, China). The arrays were imaged using an ECL system.

\section{Flow cytometry analysis}

To detect the frequency of Tregs, the following fluorescence-conjugated monoclonal antibodies and isotype controls were used: anti-CD69 (H1.2F3), antiCD25 (PC61.5), and anti-CD4 (GK1.5) (eBioscience, San Diego, CA, USA). Flow cytometry was performed using a BD FACS Calibur (BD Biosciences, San Jose, CA, USA). The data were analyzed using FCS Express V3 (De Novo Software, Los Angeles, CA, USA).

\section{Intracellular cytokine staining}

Detection of intracellular IL-2 in $\mathrm{CD} 4^{+} \mathrm{T}$ cells was performed as previously described [40]. For intracellular Foxp3 staining, cells were fixed and permeabilized using Fix and Perm reagents (Biolegend, San Diego, CA, USA), respectively, and then washed in wash buffer and stained using a PE-Cy5 anti-mouse Foxp3 staining kit (eBioscience) according to the manufacturer's instructions. 


\section{In vitro proliferation assay}

Teffs or Tregs were seeded at $1 \times 10^{4}$ cells per well in 96-well plates. After the cells were treated with or without $3 \mu \mathrm{M}$ PHA767491 in the presence or absence of anti-CD3 mAb $(2 \mu \mathrm{g} / \mathrm{ml})$ and anti-CD28 mAb $(1 \mu \mathrm{g} / \mathrm{ml})$ for $24 \mathrm{~h}$, cell proliferation was measured by CCK- 8 assay (Beyotime, Shanghai, China) at 0, 24, 72, 120 and $168 \mathrm{~h}$ according to the manufacturer's instructions. Absorbance was measured at a wavelength of $450 \mathrm{~nm}, \mathrm{OD}$. Triplicaterepeated wells for each group were measured.

\section{In vitro suppression assay}

Purified Teffs $\left(1 \times 10^{5}\right)$ were cultured with Tregs pretreated with $3 \mu \mathrm{M}$ or $5 \mu \mathrm{M}$ PHA767491 or without CDK9 inhibitor in the presence of anti-CD3 $\mathrm{mAb}(2$ $\mu \mathrm{g} / \mathrm{ml})$ and anti-CD28 $\mathrm{mAb}(1 \mu \mathrm{g} / \mathrm{ml})$ for $72 \mathrm{~h}$. Cell proliferation was assessed using a CCK-8 proliferation kit, according to the manufacturer's instructions.

\section{Western blot analysis}

Western blot analysis was performed as previously described [41]. Briefly, proteins were extracted from spleen or splenic $\mathrm{CD}^{+} \mathrm{T}$ cells from naive $\mathrm{BALB} / \mathrm{c}$ mice using lysis buffer, and the lysates were boiled for $5 \mathrm{~min}$. The samples were then separated using SDS-PAGE and transferred by electroblotting to polyvinylidene fluoride (PVDF) membranes. The membranes were probed with primary antibodies directed against CDK9 (Cell Signaling Technology, Danvers, MA, USA) or against the internal control $\beta$-actin (Santa Cruz Biotechnology, Santa Cruz, CA). The blots were then probed with horseradish peroxidase (HRP)-conjugated secondary antibodies (Santa Cruz Biotechnology), and the chemiluminescent signals were visualized using an ECL-Plus system (Millipore, Billerica, MA, USA). Signals were quantified using a GelDoc XR+ system (Bio-Rad, California, USA).

\section{Immunofluorescence}

Splenic $\mathrm{CD}^{+} \mathrm{T}$ cells were fixed in $4 \%$ paraformaldehyde and permeabilized using $0.1 \%$ Triton $\mathrm{X}-100$. The cells were subsequently stained with an anti-CDK9 antibody, and DAPI was used to stain the nuclei. The cells were then probed with Alexa Fluor 488-conjugated anti-mouse IgG (Molecular Probes). To study the effect of PHA767491 on CDK9 translocation, the cells were treated with $3 \mu \mathrm{M}$ PHA767491 or left untreated for $6 \mathrm{~h}$ and then stimulated with anti-CD3 $\mathrm{mAb}$ $(2 \mu \mathrm{g} / \mathrm{ml})$ and anti-CD28 mAb $(1 \mu \mathrm{g} / \mathrm{ml})$ for 15,30 or 60 $\mathrm{min}$. The cells were fixed and then observed under a LSM 780 fluorescence microscope (Carl Zeiss AG, Cologne,
Germany); images were captured using ZEN software.

\section{Statistical analysis}

Two-tailed t-tests were used in comparisons of two groups to evaluate differences. Survival analyses between groups were performed using the log-rank method. All results were generated using GraphPad Prism 5 software (San Diego, CA). $P$ values $<0.05$ were considered significant. Error bars reflect the standard error of the mean.

\section{ACKNOWLEDGMENTS}

None.

\section{CONFLICTS OF INTEREST}

The authors have no conflicts of interest to disclose.

\section{GRANT SUPPORT}

This work was supported by grants from the National Natural Science Foundation of China (81371601, to G.H.).

\section{REFERENCES}

1. Le Moine A, Goldman M, Abramowicz D. Multiple pathways to allograft rejection. Transplant. 2002; 73: 13731381.

2. Rocha PN, Plumb TJ, Crowley SD, Coffman TM. Effector mechanisms in transplant rejection. Immunol Rev. 2003; 196: 51-64.

3. Grazia TJ, Pietra BA, Johnson ZA, Kelly BP, Plenter RJ, Gill RG. A two-step model of acute CD4+T-cell mediated cardiac allograft rejection. J Immunol. 2004; 172: 74517458.

4. Han WR, Zhan Y, Murray-Segal LJ, Brady JL, Lew AM, Mottram PL. Prolonged allograft survival in anti-CD4 antibody transgenic mice: lack of residual helper $\mathrm{T}$ cells compared with other CD4-deficient mice. Transplant. 2000; 70: 168-174.

5. Kudlacz E, Perry B, Sawyer P, Conklyn M, McCurdy S, Brissette W, Flanagan And M, Changelian P. The novel JAK-3 inhibitor CP690550 is a potent immunosuppressive agent in various murine models. Am J Transplant. 2004; 4: 51-57.

6. Nakamura T, Nakao T, Yoshimura N, Ashihara E. Rapamycin prolongs cardiac allograft survival in a mouse model by inducing myeloid-derived suppressor cells. Am J Transplant. 2015; 15: 2364-2377.

7. Yik JH, Hu Z, Kumari R, Christiansen BA, Haudenschild DR. Cyclin-dependent kinase 9 inhibition protects cartilage 
from the catabolic effects of proinflammatory cytokines. Arthritis Rheumatol. 2014; 66: 1537-1546.

8. Keskin H, Garriga J, Georlette D, Graña X. Complex effects of flavopiridol on the expression of primary response genes. Cell Div. 2012; 7: 11.

9. Hargreaves DC, Horng T, Medzhitov R. Control of inducible gene expression by signal-dependent transcriptional elongation. Cell. 2009; 138: 129-145.

10. Schmerwitz UK, Sass G, Khandoga AG, Joore J, Mayer BA, Berberich N, Totzke F, Krombach F, Tiegs G, Zahler S, Vollmar AM, Fürst R. Flavopiridol protects against inflammation by attenuating leukocyte-endothelial interaction via inhibition of cyclin-dependent kinase 9. Arterioscler Thromb Vasc Biol. 2011; 31: 280-U121.

11. Krystof V, Baumli S, Fürst R. Perspective of cyclindependent kinase 9 (CDK9) as a drug target. Curr Pharm Des. 2012; 18: 2883-2890.

12. MacCallum DE, Melville J, Frame S, Watt K, Anderson S, Gianella-Borradori A, Lane DP, Green SR. Seliciclib (CYC202, R-Roscovitine) induces cell death in multiple myeloma cells by inhibition of RNA polymerase IIdependent transcription and down-regulation of Mcl-1. Cancer Res. 2005; 65: 5399-5407.

13. Han Y, Zhan Y, Hou G, Li L. Cyclin-dependent kinase 9 may as a novel target in downregulating the atherosclerosis inflammation. Biomed Rep. 2014; 2: 775-779.

14. Shore SM, Byers SA, Maury W, Price DH. Identification of a novel isoform of Cdk9. Gene. 2003; 307: 175-182.

15. Shore SM, Byers SA, Dent P, Price DH. Characterization of Cdk955 and differential regulation of two Cdk9 isoforms. Gene. 2005; 350: 51-58.

16. Liu H, Herrmann $\mathrm{CH}$, Chiang K, Sung TL, Moon SH, Donehower LA, Rice AP. 55K isoform of CDK9 associates with $\mathrm{Ku} 70$ and is involved in DNA repair. Biochem Biophys Res Commun. 2010; 397: 245-250.

17. Liu H, Herrmann CH. Differential localization and expression of the Cdk9 $42 \mathrm{k}$ and $55 \mathrm{k}$ isoforms. J Cell Physiol. 2005; 203: 251-260.

18. Xu J, Wang D, Zhang C, Song J, Liang T, Jin W, Kim YC, Wang SM, Hou G. Alternatively expressed genes identified in the CD4 $+\mathrm{T}$ cells of allograft rejection mice. Cell Transplant. 2011; 20: 333-350.

19. Kosugi A, Saitoh S, Narumiya S, Miyake K, Hamaoka T. Activation-induced expression of thymic shared antigen-1 on T lymphocytes and its inhibitory role for TCR-mediated IL-2 production. Int Immunol. 1994; 6: 1967-1976.

20. Tedesco-Silva H, Mourad G, Kahan BD, Boira JG, Weimar W, Mulgaonkar S, Nashan B, Madsen S, Charpentier B, Pellet P, Vanrenterghem Y. FTY720, a novel immunomodulator: efficacy and safety results from the first Phase 2A study in de novo renal transplantation. Transplant. 2005; 79: 1553-1560.

21. Herroeder S, Reichardt P, Sassmann A, Zimmermann B, Jaeneke D, Hoeckner J, Hollmann MW, Fischer KD,
Vogt S, Grosse R, Hogg N, Gunzer M, Offermanns S, Wettschureck N. Guanine nucleotide-binding proteins of the G12 family shape immune functions by controlling CD4+ T cell adhesiveness and motility. Immunity. 2009; 30: 708-720.

22. Loirand G, Guérin P, Pacaud P.'Rho kinases in cardiovascular physiology and pathophysiology. Circ Res. 2006; 98: 322-334.

23. Hölschermann H, Stadlbauer TH, Wagner AH, Fingerhuth H, Muth H, Rong S, Güler F, Tillmanns H, Hecker M. STAT-1 and AP-1 decoy oligonucleotide therapy delays acute rejection and prolongs cardiac allograft survival. Cardiovasc Res. 2006; 71: 527-536.

24. Stojanovic T, Scheele L, Wagner AH, Middel P, Bedke J, Lautenschläger I, Leister I, Panzner S, Hecker M. STAT1 decoy oligonucleotide improves microcirculation and reduces acute rejection in allogeneic rat small bowel transplants. Gene Ther. 2007; 14: 883-590.

25. Ortega $\mathrm{P}$, Morán $\mathrm{A}$, de Juan $\mathrm{C}$, Frías $\mathrm{C}$, Hernández $\mathrm{S}$, López-Asenjo JA, Sánchez-Pernaute A, Torres A, Iniesta $\mathrm{P}$, Benito M. Differential Wnt pathway gene expression and E-cadherin truncation in sporadic colorectal cancers with and without microsatellite instability. Clin Cancer Res. 2008; 14: 995-1001.

26. Sheen JH, Heeger PS. Effects of complement activation on allograft injury. Curr Opin Organ Transplant. 2015; 2: 468475.

27. Barboric M, Nissen RM, Kanazawa S, Jabrane-Ferrat $\mathrm{N}$, Peterlin BM. NF-kappaB binds P-TEFb to stimulate transcriptional elongation by RNA polymerase II. Mol Cell. 2001; 8: 327-337.

28. Nowak DE, Tian B, Jamaluddin M, Boldogh I, Vergara LA, Choudhary S, Brasier AR. RelA Ser276 phosphorylation is required for activation of a subset of NF-kappa B-dependent genes by recruiting cyclin-dependent kinase 9/cyclin T1 complexes. Mol Cell Biol. 2008; 28: 3623-3638.

29. Takada Y, Aggarwal BB. Flavopiridol inhibits NFkappaB activation induced by various carcinogens and inflammatory agents through inhibition of IkappaBalpha kinase and p65 phosphorylation: abrogation of cyclin D1, cyclooxygenase-2, and matrix metalloprotease-9. J Biol Chem. 2004; 279: 4750-4759.

30. Schmerwitz UK, Sass G, Khandoga AG, Joore J, Mayer BA, Berberich N, Totzke F, Krombach F, Tiegs G, Zahler S, Vollmar AM, Fürst R. Flavopiridol protects against inflammation by attenuating leukocyte-endothelial interaction via inhibition of cyclin-dependent kinase 9 . Arterioscler Thromb Vasc Biol. 2011; 31: 280-U121.

31. Giraud S, Hurlstone A, Avril S, Coqueret O. Implication of BRG1 and cdk9 in the STAT3-mediated activation of the p21wafl gene. Oncogene. 2004; 23: 7391-7739.

32. Hou T, Ray S, Brasier AR. The functional role of an interleukin 6-inducible CDK9.STAT3 complex in human gamma-fibrinogen gene expression. J Biol Chem. 2007; 
282: 37091-37102.

33. Laan M, Cui ZH, Hoshino H, Lötvall J, Sjöstrand M, Gruenert DC, Skoogh BE, Lindén A. Neutrophil recruitment by human IL-17 via $\mathrm{C}-\mathrm{X}-\mathrm{C}$ chemokine release in the airways. J Immunol. 1999; 162: 2347-235234.

34. Healy DG, Watson RW, O'Keane C, Egan JJ, McCarthy JF, Hurley J, Fitzpatrick J, Wood AE. Neutrophil transendothelial migration potential predicts rejection severity in human cardiac transplantation. Eur J Cardiothorac Surg. 2006; 29: 760-766.

35. Duhen T, Geiger R, Jarrossay D, Lanzavecchia A, Sallusto F. Production of interleukin 22 but not interleukin 17 by a subset of human skin-homing memory $\mathrm{T}$ cells. Nat Immunol. 2009; 10: 857-863.

36. Trifari S, Kaplan CD, Tran EH, Crellin NK, Spits H. Identification of a human helper $\mathrm{T}$ cell population that has abundant production of interleukin 22 and is distinct from $\mathrm{T}(\mathrm{H})-17, \mathrm{~T}(\mathrm{H}) 1$ and $\mathrm{T}(\mathrm{H}) 2$ cells. Nat Immunol. 2009; 10: 864-871.

37. MacCallum DE, Melville J, Frame S, Watt K, Anderson S, Gianella-Borradori A, Lane DP, Green SR. Seliciclib (CYC202, R-Roscovitine) induces cell death in multiple myeloma cells by inhibition of RNA polymerase IIdependent transcription and down-regulation of Mcl-1. Cancer Res. 2005; 65: 5399-5407.
38. Hou G, Valujskikh A, Bayer J, Stavitsky AB, Metz C, Heeger PS. In vivo blockade of macrophage migration inhibitory factor prevents skin graft destruction afterindirect allorecognition. Transplant. 2001; 72: 1890-1897.

39. Rao J, Qian X, Li G, Pan X, Zhang C, Zhang F, Zhai Y, Wang $\mathrm{X}, \mathrm{Lu}$ L. ATF3-mediated NRF2/HO-1 signaling regulates TLR4 innate immune responses in mouse liver ischemia/Reperfusion injury. Am J Transplant. 2015; 15: 76-87.

40. Pala P, Hussell T, Openshaw PJ. Flow cytometric measurement of intracellular cytokines. J Immunol Methods. 2000; 243: 107-124.

41. Zhong K, Song W, Wang Q, Wang C, Liu X, Chen D, Zhu Z, Wu Y, Zhang W, Zhang M. Murine myeloid dendritic cells that phagocytose apoptotic $\mathrm{T}$ cells inhibit the immune response via NO. PLOS ONE. 2012; 7: e49378. 